\title{
The Effects of Uncertainty Measures on the Price of Gold
}

\begin{abstract}
This paper analyzes the determinants of the price of gold with a special focus on four uncertainty measures (namely, the volatility (VIX), the skewness (SKEW), the global economic policy uncertainty (EPU), and the partisan conflict (PC) indexes). The nonlinear Autoregressive-distributed Lag (ARDL) model is used to investigate the asymmetric effect of uncertainty measures on gold prices. The results show that a worsening of economic policy uncertainty contributes to increases in the price of gold. By contrast, gold prices are less likely to fall when economic policy conditions have been improved.
\end{abstract}

Keywords: price of gold; economic policy uncertainty; VIX; partisan conflict; price of oil; real exchange rate

JEL Classification Codes: G15; D81; F31; C32 


\section{Introduction}

Gold has been traditionally used by investors as a hedge in portfolio diversification and a safe haven in times of extreme economic and political turbulence and severe_market turmoil (Baur and Lucey, 2010; Baur and McDermott, 2010; Lau et al., 2017; O’Connor et al., 2015). Gold is also a special commodity that has financial and monetary functions. Although the monetary function of gold has been weakened since the collapse of the Bretton Woods System in February 1973, the financial asset function of gold has continued its importance (Wang et al., 2016). Batten et al. (2014) suggest that gold can be viewed as an alternative to paper currency. Gold is also important to central banks and governments since it can be used as a reserve to defend the value of their currencies (Baur and McDermott, 2010).

The existing literature has shown that gold is considered as a useful tool to hedge against price risks of other financial instruments (Bredin et al., 2015; Choudhry et al., 2015; Ciner et al., 2013; Joy, 2011; Reboredo, 2013). Moreover, gold can also hedge against the inflation risk (Batten et al. 2014; Lucey et al., 2017). Baur and McDermott (2010) find evidence that gold is both a hedge and an investment safe haven, providing protection to investors against financial losses in most major developed world stock markets. Gold is considered as a safe haven since it is attractive for investors in times of the extreme market events (Baur and Lucey, 2010). In other words, gold is considered as a tool for hedging against uncertainty in the global financial system (Bialkowski et al., 2015). When there has been a sharp rise in uncertainty in the global financial system (e.g., during the global financial crisis of 2008-2009 and the European Sovereign Debt of 2011-2012), gold is considered as a safe haven asset.

In the light of the great attractiveness of gold to investors over periods of high economic and political uncertainties, there is an emerging interest in studying the role of risk perceptions and uncertainty measures on gold prices in the financial economics literature (see 
e.g. Balcilar et al., 2016; Jones and Sackley, 2016; Li and Lucey, 2017). Jones and Sackley (2016) incorporate an index of the U.S. and European EPU into a gold-pricing model and find that gold prices are positively related to EPU. The results suggest that the safe haven status of gold induces an increase of its price in times of high uncertainty. Balcilar et al. (2016) provide more evidence that gold prices react to measures of economic and political uncertainty. They suggest that changes in uncertainty measures can be a more driver of gold prices than these fundamental variables such as the price of oil and exchange rates. Li and Lucey (2017) find that EPU is a positive determinant of gold being an investment safe haven. While a substantial number of studies examine the determinants of gold prices, little research has considered the effect of economic and political uncertainties on the gold price (see O'Connor et al., 2015, for a review of relevant literature).

Inspired by the recent studies of Jones and Sackley (2016), Balcilar et al. (2016), and Li and Lucey (2017), our paper investigates the determinants of gold prices with a special focus on four different uncertainty measures. Our research examines the effects of the volatility (VIX), the skewness (SKEW), the global economic policy uncertainty (EPU), and the partisan conflict (PC) indexes on the price of gold. The study also considers the effects of exchange rates and crude oil prices. First, following Capie et al. (2005), O'Connor and Lucey (2012), and Pukthuanthong and Roll (2011), the effect of the exchange rate (real value of U.S. dollar) has been accounted for to capture the financial function of the gold. Second, following Ciner et al. (2013), Gil-Alana et al. (2017), Kang et al. (2013), and Reboredo (2013), the price of crude oil has also been considered since crude oil and gold are close substitutes as safe haven assets.

Our paper contributes to the existing literature in two ways. First, the few existing studies provide some evidence that gold prices are sensitive to certain uncertainty measures. It is not yet clear, however, how broad measures of economic and political uncertainty affect 
gold prices. To the best knowledge of the authors, this is the first paper to analyze the effects of four uncertainty measures on gold price fluctuations. By including different uncertainty measures this research provides rich insights into the determinants of gold prices and the safe haven role of gold. For example, the SKEW index captures the tail risk (the risk of outlier returns two or more standard deviations below the mean) in the S\&P 500 stock markets (Gozgor, 2014). The partisan conflict index, which represents the degree of political disagreement among U.S. politicians at the federal level, is of great significance as a measure of economic and political uncertainty especially in recent years when there has been a high degree of partisan conflict in American politics.

Second, our paper is the first to investigate asymmetric effects of uncertainty measures on gold prices. This study considers the asymmetric effect in the sense that the partial sum positive and negative change of uncertainty measures can have different impacts on the price of gold. A novel Nonlinear Autoregressive Distributed Lag (NARDL) Model proposed by Sin et al. (2014) is employed in this study, which introduces an asymmetric structure in the specification of the gold price. This paper also uses the recent developed Generalized Autoregressive Conditional Heteroskedasticity $(\mathrm{GARCH})$ based unit root test of Narayan and Liu (2015) to test for stationarity of the variables of interest.

The remainder of this paper is organized as follows: Section 2 provides a brief review of relevant literature, Section 3 explains the data, methodologies, and models, Section 4 presents empirical results and discussion, Section 5 summarizes and concludes.

\section{Literature Review}

There have been extensive studies on gold as an investment and its relation to inflation, exchange rates, oil prices, and other variables. This section only elaborates on a few selected papers. O'Connor et al. (2015) provide a good review of relevant literature. Ewing 
and Malik (2013), for instance, investigate the volatility transmission between gold and oil futures under structural breaks by employing univariate and bivariate GARCH models. Ewing and Malik (2013) find evidence of significant transmissions of volatility between gold and oil returns. Their findings also support the idea of the cross-market hedging and sharing of the common information by financial market participants. Barunik et al. (2016) analyze dynamic correlations between pairs of key traded assets (gold, oil, and stocks) using both intra-day and daily data. The results show that the heterogeneity in correlations across various investment horizons is a dominant feature during times of economic downturn and financial turbulence for all three pairs of the assets under research. Gil-Alana et al. (2017) also examine comovements of gold and oil prices using a fractional cointegration approach. The results show that there exists a fractionally cointegrated relationship between the two variables, with an order of integration in the long-run relationship of about 0.46 . Furthermore, gold price shocks seem to have an impact on oil prices that persists in time. The effects of foreign exchange risk on prices of gold and other commodities have been also studied in the literature. For instance, Beckmann et al. (2015) investigate causal relationships and volatility patterns between gold prices and exchange rates. This study reports that the gold price is likely to increase after a depreciation of U.S. dollars. Moreover, increasing volatility of dollar exchange rates can cause substantial financial losses for investors. However, gold is able to offset these losses. Furthermore, Khalifa et al. (2016) analyze volatility transmission mechanisms between exchange rates and seven commodities (i.e., oil, gold, silver, copper, platinum, palladium, and aluminum) with the U.S. uncertainty measures. They report the presence of uncertainty measures can change volatility transmission patterns. However, their research mainly focuses on the patterns of volatility transmissions between asset classes with and without impacts of uncertainty measures and only use lagged uncertainty measures as control variables. 
Batten et al. (2010), on the other hand, focus on the macroeconomic determinants (business cycles, financial market sentiment, and monetary environment) of the volatility in precious metals (the prices of gold, palladium, platinum, and silver) markets by using the monthly price volatility values. The results show that the volatility of gold can be explained by the monetary variables. Moreover, Batten et al. (2014) analyze economic determinants of the gold-inflation relation by examining the long-term dynamic relation between inflation and the gold price. The research shows that there is no cointegration between the price of the gold and inflation when a volatile period of the early 1980s is excluded from the data. However, Batten et al. (2014) demonstrate that the co-movement between the variables has increased during the 2000s.

\section{Data, Econometric Methodology, and Empirical Model}

\subsection{Data}

Our paper considers the price of gold as the dependent variable over the period from January 1997-May 2017. The data for the price of the gold is obtained from the Bloomberg terminal. The monthly frequency data are used. The price of oil is the spot oil price of the Cushing WTI and the data are provided by the U.S. Energy Information Administration. The REER is the index of the real (broad) effective exchange rate for the U.S. $(2010=100)$, and the data are obtained from the Bank for International Settlements. The VIX and the SKEW indexes are the monthly averages of the daily data and the data acquired from the Chicago Board Options Exchange (CBOE). The original monthly partisan conflict index is also used in the estimations and the data are obtained from the Federal Reserve Bank of Philadelphia. The global Economic Policy Uncertainty (EPU) index (the purchasing power parity (PPP)adjusted gross domestic product (GDP) weights), which are proposed by Baker et al. (2016), 
are also used in the estimations. ${ }^{1}$ In addition, following previous papers, we use the variables in the natural logarithmic form in the empirical analysis. ${ }^{2}$ Finally, a summary of the descriptive statistics and the description of the variables are provided in Appendix I, and the correlation matrix is reported in Appendix II.

\subsection{Econometric Methodology and Empirical Models}

\subsubsection{Unit Root Tests}

We test for stationarity of the variables of interest in this section, the hypothesis of the absence of a unit root are examined by employing the Augmented Dickey-Fuller (ADF) test of Dickey and Fuller (1979), the tests of Phillips and Perron (PP) developed by Phillips and Perron (1988), and the structural breaks model test by Zivot and Andrews (1992). We also consider the KPSS test of the null hypothesis of stationarity. It is well known that both the $\mathrm{ADF}$ and the PP tests are lack of power in testing for a unit root in the time series variable; and therefore, we further apply the nonlinear unit root test of the KSS test of Kapetanios et al. (2003) to test for unit roots when the nonlinear component is significant. ${ }^{3} \mathrm{We}$ also apply another more powerful unit root test of Narayan and Liu (2015) that considers the GARCHbased unit root test. The results of the unit root test of Narayan and Liu (2015) can be noteworthy since the monthly data on our models can be volatile.

The choice of the KSS nonlinear unit root test is based on the fact that the nonlinear exponential smooth transition autoregressive (ESTAR) model, as proposed by Granger and Teräsvirta (1993), which is the most popular nonlinear model in the literature due to its theoretical and modelling advance. The model not only be able to mimic the hidden nonlinear components in time series data, but it can also provide a theoretical rationale to model the

\footnotetext{
${ }^{1}$ For the details of the EPU indexes, visit the website that designed by Scott R. Baker, Nick Bloom, and Steven J. Davis (http://www.policyuncertainty.com).

${ }^{2}$ We try to stick up to previous papers and they suggest that the uncertainty measures should be considered in the natural logarithmic form (see e.g. Jones and Sackley, 2016).

${ }^{3}$ The power of ADF test is criticized as lack of power in rejecting near unit root series, resulting in over not rejecting of a unit root, especially when the series of interest follow nonlinear threshold process and contain significant nonlinear components (Lau et al., 2012; Taylor, 2001).
} 
hidden market frictions during the trading activity, such as imperfect market structures and the transportation costs. Following Kapetanios et al. (2003), we can specify the model as such:

$$
\Delta y_{t}=\xi y_{t-1}\left[1-\exp \left(\theta y_{t-1}^{2}\right)\right]+\mu_{t} ; \mu_{t} \sim I I D\left(0, \sigma^{2}\right)
$$

Where $\xi$ and $\theta$ are the parameters, which govern the dynamics of the data generating process. However $\xi$ is not identified under the null hypothesis; and therefore, the null hypothesis cannot be tested. Using a first-order Taylor series approximation method, Kapetanios et al. (2003) reparametrize Equation (1) and the auxiliary regression becomes the following:

$$
\Delta \mathrm{y}_{\mathrm{t}}=\phi \mathrm{y}_{\mathrm{t}-1}^{3}+\mu_{\mathrm{t}}
$$

$\phi$ is the KSS test parameter, the t-statistics could be derived from $\phi$, which is denoted by:

$$
t_{K S S}=\frac{\widehat{\phi}}{\operatorname{se}(\widehat{\phi})}
$$

where $\widehat{\phi}$ is the ordinary least squares (OLS) estimate of $\phi$, and $s e(\hat{\phi})$ is its associated standard error.

\subsubsection{Nonlinear Autoregressive Distributed Lag (NARDL) Model}

We examine the dynamic response of the gold price to six independent variables (i.e. the oil price, the real effective exchange rate, the VIX, the SKEW, the partisan conflict, and the global economic policy uncertainty indexes). There are two motivations to apply the NARDL method in our paper. First, the results on the stationarity of variables are mixed in the previous section; therefore, the NARDL model provides robust estimations even with the mixed integration of variables in the system. Second, the gold price appeases to exhibit an asymmetric long-run and short-run response to six independent variables of interest. The NARDL model is introduced by Sin et al. (2014), and the long-run specification of the gold price can be written as such: 


$$
\begin{aligned}
& \ln (G P)=\alpha_{0}+\alpha_{1} \ln (O P)_{t}^{+}+\alpha_{2} \ln (O P)_{t}^{-}+\alpha_{3} \ln (R E E R)_{t}^{+}+\alpha_{4} \ln (R E E R)_{t}^{-}+ \\
& \alpha_{5} \ln (V I X)_{t}^{+}+\alpha_{6} \ln (V I X)_{t}^{-}+\alpha_{7} \ln (S K E W)_{t}^{+}+\alpha_{8} \ln (S K E W)_{t}^{-}+\alpha_{9} \ln (P C I)_{t}^{+}+ \\
& \alpha_{10} L N(P C I)_{t}^{-}+\alpha_{11} \ln (E P U)_{t}^{+}+\alpha_{12} L N(E P U)_{t}^{-}+\varepsilon_{t}
\end{aligned}
$$

where variables $G P, O P, R E E R, V I X, S K E W, P C I$, and $E P U$ represent the oil price, the gold price, the real effective exchange rate (REER) in the USD, the Chicago Board Options Exchange (CBOE) the Volatility Index, the Chicago Board Options Exchange (CBOE) the SKEW index, the partisan conflict index, and the global economic policy uncertainty (EPU) index, respectively. The partial sum positive and negative change of variables in interest can be represented by the positive and the negative signs, respectively. For example, the partial sums for changes in the oil price can be expressed as such:

$$
\begin{aligned}
& o p_{t}^{+}=\sum_{i=1}^{t} \Delta o p_{i}^{+}=\sum_{i=1}^{t} \max \left(\Delta o p_{i}^{+}, 0\right) \\
& o p_{t}^{-}=\sum_{i=1}^{t} \Delta o p_{i}^{-}=\sum_{i=1}^{t} \min \left(\Delta o p_{i}^{-}, 0\right)
\end{aligned}
$$

According to the literature, the long-run relation between the gold price and the oil price is positive; i.e. a higher level of oil price increases the gold prices. A higher level of the REER implies the appreciation of the USD; and therefore, a higher level of the REER is expected to decrease the price of the gold. The effects of uncertainty measures (e.g. the VIX, the SKEW, the partisan conflict, and the global EPU indexes) can be either negative or positive. During normal periods, a higher level of uncertainty should be negatively related to the asset prices. However, given that gold can be seen as the "safe haven" by the investors, especially during the times of high uncertainty, we can suggest that there can be positive effects of uncertainty measures on the price of gold. These asymmetric effects need to be modeled, and the NARDL estimations can successfully capture the asymmetric effects. Following Shin et al. (2014), Equation (4) for the NARDL model can be rewritten as such:

$$
\begin{array}{r}
\ln (G P)=\alpha_{0}+\alpha_{1} \ln (O P)_{t}^{+}+\alpha_{2} \ln (O P)_{t}^{-}+\alpha_{3} \ln (R E E R)_{t}^{+}+\alpha_{4} \ln (R E E R)_{t}^{-}+ \\
\alpha_{5} \ln (V I X)_{t}^{+}+\alpha_{6} \ln (V I X)_{t}^{-}+\alpha_{7} \ln (S K E W)_{t}^{+}+\alpha_{8} \ln (S K E W)_{t}^{-}+\alpha_{9} \ln (P C I)_{t}^{+}+
\end{array}
$$




$$
\begin{aligned}
& \alpha_{10} L N(P C I)_{t}^{-}+\alpha_{11} \ln (E P U)_{t}^{+}+\alpha_{12} L N(E P U)_{t}^{-}+\sum_{i=1}^{j} \gamma_{i} \Delta G P_{t-i}+\sum_{i=1}^{P}\left(\theta_{i}^{+} \Delta O P_{t-1}^{+}+\right. \\
& \left.\theta_{i}^{-} \Delta O P_{t-1}^{-}\right)+\sum_{i=1}^{q}\left(\delta_{i}^{+} \Delta R E E R_{t-1}^{+}+\delta_{i}^{-} \Delta R E E R_{t-1}^{-}\right)+\sum_{i=1}^{m}\left(\varphi_{i}^{+} \Delta V I X_{t-1}^{+}+\varphi_{i}^{-} \Delta V I X_{t-1}^{-}\right)+ \\
& \sum_{i=1}^{n}\left(\varpi_{i}^{+} \Delta S K E W_{t-1}^{+}+\varpi_{i}^{-} \Delta S K E W_{t-1}^{-}\right)+ \\
& \sum_{i=1}^{k}\left(\psi_{i}^{+} \Delta P C I_{t-1}^{+}+\psi_{i}^{-} \Delta P C I_{t-1}^{-}\right)+\sum_{i=1}^{s}\left(\xi_{i}^{+} \Delta E P U_{t-1}^{+}+\xi_{i}^{-} \Delta E P U_{t-1}^{-}\right)+\varepsilon_{t}
\end{aligned}
$$

\section{Empirical Results and Discussion}

In order to examine the unit root test hypothesis, we perform several conventional univariate unit root tests, including the Augmented Dickey-Fuller test (ADF, Dickey and Fuller, 1979), the PP test (Phillips and Perron, 1988), the KPSS test (Kwiatkowski et al., 1992), and the structural breaks model test by Zivot and Andrews (1992). We also apply the nonlinear unit root test of Kapetanios et al. (2003). The KSS unit root test is more powerful than the conventional unit root test when the data contain a significant nonlinear component. Finally, we use the GARCH-based unit root test of Narayan and Liu (2015) to model the volatility in the monthly data. The result in Table 1 regarding the evidence of is more mixed, rather than stationary, and I (2) variables are in the absence in our study; and therefore, it is statistically appropriate to estimate the NARDL model in Equation (7).

\section{[Insert Table 1 around here]}

We estimate the static linear regression and the static asymmetric model as the baseline models. As reported in Table 2, the results clearly indicate that asymmetric model is the appropriate one and the results of the asymmetric test also confirm this for all independent variables. ${ }^{4}$ The results of the cointegration of Shin et al. (2014) show that all variables included in our estimates model co-move in the long-run. The cointegration test statistic of $\mathrm{t}_{\mathrm{BDM}}$ (i.e.-3.934) is able to reject the null hypothesis of no cointegration at the $5 \%$ significance

\footnotetext{
${ }^{4}$ The results are not reported here to save space, but available upon request.
} 
level. ${ }^{5}$ As there is evidence of co-movement in the system, we further examine the dynamic relation between the gold price and the positive and the negative changes in the oil price, the REER, the VIX, the SKEW index, the partisan conflict index, and the global EPU index.

\section{[Insert Table 2 around here]}

Table 3 shows the long-run asymmetry tests and the asymmetric long-run response of the gold price to the positive and the negative changes in other variables. We obtain the positive response of the gold price to the positive and the negative changes in oil price. ${ }^{6} \mathrm{We}$ observe the negative response of the gold price to positive change in the real effective exchange rate, and the positive response of the gold price to the negative change in the VIX. Finally, we observe the positive response of the gold price to the positive change in the global EPU, and the negative response of the gold price to the negative change in the global EPU.

\section{[Insert Table 3 around here]}

According to the results in Table 4, the long-run response of the gold price to the change in the oil price is statistically significant for both directions of the oil price change; even the response to the negative oil price shock is two times larger than that of the positive oil price shock in its magnitude. The findings from the nonlinear Autoregressive Distributed Lag (ARDL) estimations indicate that there is a positive response to the price of gold to the negative changes in the price of oil. L.x1p and L.x1n denote the long-run coefficients associated with the positive and the negative changes of oil price, respectively. The coefficients of the asymmetric long-run multipliers (L.x1p and L.x1) are both statistically significant, exhibiting the speed of adjustment to the equilibrium after a shock. The estimated long-run coefficients L.x1p and L.x $1 \mathrm{n}$ are determined as 0.276 and -0.455 , respectively. The findings imply that a one percent increase in the oil price leads to a 0.276 percent rise in gold

\footnotetext{
${ }^{5}$ Both the Trace and Maximum Eigenvalue tests in the static cointegration (i.e. the Johansen cointegration test) also indicate that all variables included in our estimates model co-move in the long-run. The related results are not reported on here, but available upon request.

${ }^{6}$ However, the response of the gold price to the oil price is larger for the decrease in the oil price.
} 
price and one percent decrease in oil price leads to a 0.455 increase in the price of gold. As gold does not provide cash flows, such as dividend on equities, an accurate prediction on gold price changes is important for investors in the gold market to generate high return. The Goldoil relation is partly due to inflation (an increase in oil price is a proxy for inflation) (Batten et al., 2010 and 2014). Indeed, as a high spike in oil prices would accelerate inflation, the central banks will invest more in physical gold in order to minimize the risk is related to currency devaluation, resulted in the increase in gold price. However, if oil dramatically fell, the global gold prices may increase as in the reality that the gold price was increased in Britain for three major periods of deflation: 1814-1830, 1864-1897, and 1929-1933 (Jastram and Leyland, 2009). Investors and households prefer to keep their money outside the banking system and invest in the gold market; our findings on the gold-oil relation are consistent with the above explanations.

\section{[Insert Table 4 around here]}

Regarding the gold-exchange rate relation, the higher level of the REER implies the appreciation of the USD; and therefore, the higher level of the REER is expected to decrease the price of the gold, as gold has served as the hedge against fluctuations in the foreign exchange value of the USD (Capie et al., 2005; Joy, 2011; Pukthuanthong and Roll, 2011). The estimated long-run coefficients for the real effective exchange rate (i.e. L.x2p) is determined as -0.496 . The finding implies a one percent increase in the real effective exchange rate for USD causes a 0.496 percent decrease in the gold price.

In regard to the gold-price movements, it is interesting to examine how the gold price reacts to economic and political uncertainty. In the paper of Balcilar et al. (2016) and Jones and Sackley (2016), the authors find evidence of the causality running from various uncertainty measures to gold returns. In our paper, we also find the evidence of the positive response of the gold price to the positive change in the global EPU, and the negative response 
of the gold price to the negative change in the global EPU (even statistically insignificant), confirming the fact that worsening in economic and political uncertainty is likely to increase the gold price, while improving in economic and political uncertainty the gold price is not necessary to fall..

The above empirical results imply the validity of the substitution effect between the gold and oil. We also observe the negative response of the price of gold to the positive change in the REER and this finding is in line with the theoretical expectation, i.e. a weak dollar can cause to a higher price of the gold. In addition, we obtain the positive response of the gold price to the negative change in the VIX. Finally, we find the positive response of the gold price to the positive change in the global EPU and the negative response of the gold price to the negative change in the global EPU. This result implies that gold is considered as the safe haven in the times of high-level economic policy uncertainty in the world. Therefore, in addition to gold being a hedge against inflation, increases in economic policy uncertainty contribute to increases in the price of gold, and the decrease in economic policy uncertainty will not have the significant decrease in the gold price. In short, we observe the co-movement between the price of the gold and the global EPU. Therefore, we can suggest that the price of gold is not only crucial for the asset pricing, but also for the portfolio diversification and risk management not matter at the time of increasingly uncertain economic policy environment or normal episodes.

The results of the nonlinear ARDL test reveal that positive shock in the real exchange rate and economic policy uncertainty has a more pronounced effect than negative shocks to the price of the gold, while the gold price is relatively more sensitive to decreases in oil prices. We, therefore, conclude that the interactive mechanism between oil, exchange rate, economic policy uncertainty and gold prices is nonlinear and asymmetric. Finally, Figure 1 
presents the dynamic multipliers for the long-run asymmetry and the results confirm this baseline evidence.

\section{[Insert Figure 1 around here]}

\section{Conclusion}

In this paper, we analyze the determinants of the price of gold with a special focus on four uncertainty measures (i.e., the VIX, the SKEW, the global EPU, and the PC indexes). In the empirical model, we consider the REER of the U.S. dollar and the price of oil. We utilize the nonlinear ARDL estimations, and the findings show that gold prices respond positively to negative changes of the oil price. This result implies the validity of the substitution effect between gold and oil. We also observe that gold prices tend to react negatively to a positive change in the REER, and this finding is in line with the theoretical expectation, i.e. a weak dollar leads to a higher price of gold. In addition, we find a positive response of the gold price to negative changes in the VIX. Finally, we find a positive response of gold prices to positive changes of the global EPU and a negative response of gold prices to negative changes in the global EPU. This result suggests that gold is considered as a safe haven in times of high-level economic policy uncertainties in the world. In short, we observed the co-movement between the price of the gold and the global EPU. The findings of this paper offer great insights into practices of the portfolio diversification and risk management.

Future research on the determinants of the gold price can consider other uncertainty measures. At this stage, the U.S. economic policy uncertainty, especially the monetary policy uncertainty and the fiscal policy uncertainty in the U.S. can be considered as the potential drivers of the price of the gold. 


\section{References}

Baker, S.R., Bloom, N., \& Davis, S.J. (2016). Measuring Economic Policy Uncertainty. Quarterly Journal of Economics, 131 (4), 1593-1636.

Balcilar, M., Gupta, R., \& Pierdzioch, C. (2016). Does Uncertainty Move the Gold Price? New Evidence from a Nonparametric Causality-in-quantiles Test. Resources Policy, $49,74-80$.

Barunik, J., Kočenda, E., \& Vácha, L. (2016). Gold, Oil, and Stocks: Dynamic Correlations. International Review of Economics and Finance, 42, 186-201.

Batten, J.A., Ciner, C., \& Lucey, B.M. (2010). The Macroeconomic Determinants of Volatility in Precious Metals Markets. Resources Policy, 35 (2), 65-71.

Batten, J.A., Ciner, C., \& Lucey, B.M. (2014). On the Economic Determinants of the GoldInflation Relation. Resources Policy, 41, 101-108.

Baur, D.G., \& Mcdermott, T.K. (2010). Is Gold a Safe Haven? International Evidence. Journal of Banking and Finance, 34, 1886-1898.

Baur, D. G., \& Lucey, B. M. (2010). Is gold a hedge or a safe haven? An analysis of stocks, bonds and gold. Financial Review, 45(2), 217-229.

Beckmann, J., Czudaj, R., \& Pilbeam, K. (2015). Causality and Volatility Patterns between Gold Prices and Exchange Rates. The North American Journal of Economics and Finance, 34, 292-300.

Bialkowski, J., Bohl, M.T., Stephan, P.M., \& Wisniewski, T.P. (2015). The Gold Price in Times of Crisis. International Review of Financial Analysis, 41, 329-339.

Bredin, D., Thomas, C., \& Potì, V. (2015). Does Gold Glitter in the Long-Run? Gold as a Hedge and Safe Haven across Time and Investment Horizon. International Review of Financial Analysis, 41, 320-328. 
Capie, F., Mills, T.C., \& Wood, G. (2005). Gold as a Hedge against the Dollar. Journal of International Financial Markets, Institutions and Money, 15 (4), 343-352.

Choudhry, T., Hassan, S.S., \& Shabi, S. (2015). Relationship between Gold and Stock Markets during the Global Financial Crisis: Evidence from Nonlinear Causality Tests. International Review of Financial Analysis, 41, 247-256.

Ciner, C., Gurdgiev, C., \& Lucey, B.M. (2013). Hedges and Safe Havens: An Examination of Stocks, Bonds, Gold, Oil and Exchange Rates. International Review of Financial Analysis, 29, 202-211.

Dickey, D.A., \& Fuller, W.A. (1979). Distribution of the Estimators for Autoregressive Time Series with a Unit Root. Journal of the American Statistical Association, 74 (366), $427-431$.

Ewing, B.T., \& Malik, F. (2013). Volatility Transmission between Gold and Oil Futures under Structural Breaks. International Review of Economics and Finance, 25, 113121.

Gil-Alana, L.A., Yaya, O.S., \& Awe, O.O. (2017). Time Series Analysis of Co-movements in the Prices of Gold and Oil: Fractional Cointegration Approach. Resources Policy, 53, $117-124$.

Gozgor, G. (2014). Determinants of Domestic Credit Levels in Emerging Markets: The Role of External Factors. Emerging Markets Review, 18, 1-18.

Gozgor, G., Lau, C.K.M., \& Bilgin, M.H. (2016). Commodity Markets Volatility Transmission: Roles of Risk Perceptions and Uncertainty in Financial Markets. Journal of International Financial Markets, Institutions and Money, 44, 35-45.

Granger, C.W., \& Terasvirta, T. (1993). Modelling Non-Linear Economic Relationships. Oxford University Press: Oxford. 
Jastram, R.W., \& Leyland, J. (2009). The Golden Constant: The English and American Experience 1560-2007. Updated Edition, Edward Elgar: Cheltenham.

Jones, A.T., \& Sackley, W.H. (2016). An Uncertain Suggestion for Gold-Pricing Models: The Effect of Economic Policy Uncertainty on Gold Prices. Journal of Economics and Finance, 40 (2), 367-379.

Joy, M. (2011). Gold and the US Dollar: Hedge or Haven? Finance Research Letters, 8, 120131.

Kang, S.H., Mciver, R., \& Yoon, S-M. (2017). Dynamic Spillover Effects among Crude Oil, Precious Metal, and Agricultural Commodity Futures Markets. Energy Economics, 62, $19-32$.

Kapetanios, G., Shin, Y., \& Snell, A. (2003). Testing For a Unit Root in the Nonlinear STAR Framework. Journal of Econometrics, 112 (2), 359-379.

Khalifa, A.A.A., Otranto, E., Hammoudeh, S., \& Ramchander, S. (2016). Volatility Transmission across Currencies and Commodities with US Uncertainty Measures. The North American Journal of Economics and Finance, 37, 63-83.

Kwiatkowski, D., Phillips, P.C.B., Schmidt, P., \& Shin, Y. (1992). Testing the Null Hypothesis of Stationarity against the Alternative of a Unit Root: How sure are we that Economic Time Series Have a Unit Root? Journal of Econometrics, 54 (1-3), 159178.

Lau, M.C.K., Suvankulov, F., Su, Y., \& Chau, F. (2012). Some Cautions on the Use of Nonlinear Panel Unit Root Tests: Evidence from a Modified Series-Specific NonLinear Panel Unit-Root Test. Economic Modelling, 29 (3), 810-816.

Lau, M.C.K., Vigne, S.A., Wang, S., \& Yarovaya, L. (2017). Return Spillovers between White Precious Metal ETFs: The Role of Oil, Gold, and Global Equity. International Review of Financial Analysis, 52, 316-332. 
Li, S., \& Lucey, B.M. (2017). Reassessing the Role of Precious Metals as Safe Havens-What Colour is your Haven and Why? Journal of Commodity Markets, 7, 1-14.

Lucey, B.M., Sharma, S.S., Vigne, S.A. (2017). Gold and Inflation(s) - A Time-varying Relationship. Economic Modelling, 67, 88-101.

Narayan, P.K., \& Liu, R. (2015). A Unit Root Model for Trending Time-series Energy Variables. Energy Economics, 50, 391-402.

Newey, W.K., \& West, K.D. (1994). Automatic Lag Selection in Covariance Matrix Estimation. Review of Economic Studies, 61 (4), 631-653.

O’Connor, F.A., Lucey, B.M., Batten, J.A., \& Baur, D.G. (2015). The Financial Economics of Gold - A Survey. International Review of Financial Analysis, 41, 186-205.

Phillips, P.C.B., \& Perron, P. (1988). Testing For a Unit Root in Time Series Regression. Biometrika, 75 (2), 335-346.

Pukthuanthong, K., \& Roll, R. (2011). Gold and the Dollar (and the Euro, Pound, and Yen). Journal of Banking and Finance, 35 (8), 2070-2083.

Reboredo, J.C. (2013). Is Gold a Safe Haven or a Hedge for the US Dollar? Implications for Risk Management. Journal of Banking and Finance, 37, 2665-2676.

Shin, Y., Yu, B., \& Greenwood-Nimmo, M. (2014). Modelling Asymmetric Cointegration and Dynamic Multipliers, In a Nonlinear ARDL Framework. In Festschrift In Honor Of Peter Schmidt, (pp. 281-314), Springer: New York, NY.

Smales, L.A. (2014). Political Uncertainty and Financial Market Uncertainty in an Australian Context. Journal of International Financial Markets, Institutions and Money, 32, 415435.

Taylor, A.M. (2001). Potential Pitfalls for the Purchasing-power Parity Puzzle? Sampling and Specification Biases in Mean-reversion Tests of the Law of One Price. Econometrica, $69(2), 473-498$. 
Vigne, S.A., Lucey, B.M., O’Connor, F.A. \& Yarovaya, L. (2017). The Financial Economics of White Precious Metals — A Survey. International Review of Financial Analysis, $52,292-308$.

Wang, G-J., Xie, C., Jiang, Z.Q., \& Stanley, H.E. (2016). Extreme Risk Spillover Effects in World Gold Markets and the Global Financial Crisis. International Review of Economics and Finance, 46, 55-77.

Zivot, E., \& Andrews, D.W.K. (1992). Further Evidence on the Great Crash, the Oil-price Shock, and the Unit-root Hypothesis. Journal of Business and Economic Statistics, 10 (3), 251-270. 
Table 1.

Results of the Univariate Unit Root Tests

\begin{tabular}{|c|c|c|c|c|c|c|c|c|c|}
\hline \multicolumn{4}{|c|}{ Univariate Unit Root Test/stationarity Test } & \multicolumn{2}{|c|}{ Innovational Outlier Test (ZA) } & \multicolumn{3}{|c|}{ Nonlinear ESTAR Unit Root Test } & \multirow{2}{*}{$\begin{array}{l}\text { GARCH-based Unit Root Test of } \\
\text { Narayan and Liu (2015) }\end{array}$} \\
\hline ETFs & $\mathrm{ADF}$ & $\mathrm{PP}$ & KPSS & Model A & Break Date & KSS1 & KSS2 & KSS3 & \\
\hline $\ln$ (gold) & -1.6232 & -1.5253 & $0.2378 * * *$ & -4.8940 & August 2009 & -2.1706 & -0.8746 & 1.6212 & -2.7282 \\
\hline $\ln ($ oil $)$ & -1.8053 & -1.7053 & $0.3565 * * *$ & -4.4413 & August 2011 & -2.2305 & -1.6924 & -0.3180 & -1.8241 \\
\hline $\ln ($ reer $)$ & -1.3421 & -1.5800 & $0.2477 * * *$ & -3.5867 & June 2010 & -1.6734 & -1.7255 & 0.1789 & -0.7717 \\
\hline $\ln ($ vix $)$ & $-4.0966 * * *$ & $-4.5631 * * *$ & 0.1157 & $-6.8874 * * *$ & May 2007 & -2.2906 & $-2.8167 *$ & -1.3742 & $-4.6212 * * *$ \\
\hline $\ln ($ skew $)$ & $-1.2317 * * *$ & $-8.3942 * * *$ & $0.1772 * * *$ & $-6.8107 * * *$ & May 2007 & $-5.9764 * * *$ & $-4.6711 * * *$ & 0.2578 & $-7.2511 * * *$ \\
\hline $\ln (\mathrm{pci})$ & -3.3488 & $-5.9591 * * *$ & $0.3493 * * *$ & -4.0875 & December 2009 & $-5.9323 * * *$ & $-3.5095 * * *$ & -0.0683 & $-3.3539 * * *$ \\
\hline $\ln ($ epu $)$ & $-3.4267 *$ & $-4.7561 * * *$ & $0.1660 * * *$ & $-6.3117 * * *$ & March 2003 & $-4.0897 * * *$ & $-3.4156^{* *}$ & -0.5395 & $-4.3522 * * *$ \\
\hline
\end{tabular}

Notes: For the PP and the KPSS tests, the selected truncations for the Bartlett Kernel are based on the suggestion by Newey and West (1994). The optimum lag order is selected based on the BIC criterion. The unit root test of Zivot and Andrews (1992) considers the break in the intercept of the linear trend function. We extract the appropriate critical values (CVs) from Narayan and Lui (2015) for the $1 \%, 5 \%$, and $10 \%$ levels respectively. ***, **, and *denote the statistical significance at the $1 \%$., $5 \%$, and $10 \%$ level. 
Table 2.

Results of the Static Estimation of the Gold-Uncertainty Variables Relationship

\begin{tabular}{|c|c|c|c|c|c|}
\hline \multicolumn{3}{|c|}{ Static Linear Regression } & & \multicolumn{2}{|c|}{ Static Asymmetric Regression } \\
\hline & Estimated Coefficient & $\mathrm{P}$-value & & Estimated Coefficient & P-value \\
\hline $\ln ($ oil $)$ & -0.0275 & 0.295 & $\ln ($ oil $)+$ & 0.0878764 & 0.026 \\
\hline $\ln ($ reer $)$ & -3.2943 & 0.000 & $\ln ($ oil $)-$ & -0.195927 & 0.000 \\
\hline $\ln ($ vix $)$ & 0.0395 & 0.145 & $\ln ($ reer $)+$ & -2.427841 & 0.000 \\
\hline $\ln ($ skew $)$ & 0.0361 & 0.817 & $\ln ($ reer $)-$ & -3.292246 & 0.000 \\
\hline $\ln (\mathrm{pci})$ & -0.0266 & 0.526 & $\ln (\operatorname{vix})+$ & -0.1474827 & 0.000 \\
\hline $\ln ($ epu $)$ & 0.1920 & 0.000 & $\ln (\operatorname{vix})_{-}$ & 0.0735228 & 0.01 \\
\hline Constant & 0.0061 & 0.000 & $\ln ($ skew $)+$ & 0.1671815 & 0.223 \\
\hline Trend & 20.2352 & 0.000 & $\ln ($ skew $)-$ & -0.3400127 & 0.03 \\
\hline $\mathrm{R}^{2}$ & 0.9788 & & $\ln ($ pci $)+$ & -0.1157575 & 0.007 \\
\hline \multirow[t]{6}{*}{ Adj. $R^{2}$} & 0.9782 & & $\ln (\mathrm{pci})-$ & 0.0408132 & 0.281 \\
\hline & & & $\ln (\mathrm{epu})+$ & 0.239445 & 0.000 \\
\hline & & & $\ln (\mathrm{epu})-$ & 0.1051155 & 0.004 \\
\hline & & & Constant & 5.79518 & 0.000 \\
\hline & & & $\mathrm{R}^{2}$ & 0.9865 & \\
\hline & & & Adj. $R^{2}$ & 0.9858 & \\
\hline
\end{tabular}

Note: In order to accommodate the strong trending behavior of variables, we include a deterministic time trend in the symmetric case. 
Table 3.

Results of the Long-run Asymmetry Tests

Long-Run Effect (+ve) Long-Run Effect(-ve)

\begin{tabular}{lrrrr}
\hline & Coefficient & \multicolumn{1}{c}{ P-value } & Coefficient & P-value \\
\hline $\ln$ (oil) & 0.620 & 0.017 & 1.022 & 0.000 \\
$\ln ($ reer $)$ & -11.16 & 0.000 & 0.334 & 0.746 \\
$\ln ($ vix $)$ & -0.241 & 0.125 & 0.331 & 0.089 \\
$\ln ($ skew $)$ & 0.838 & 0.503 & -0.837 & 0.577 \\
$\ln ($ pci $)$ & -0.108 & 0.816 & 0.162 & 0.703 \\
$\ln ($ epu $)$ & 0.301 & 0.018 & -0.423 & 0.092 \\
\hline Long-run asymmetry test & & Short-run asymmetry test
\end{tabular}

\begin{tabular}{lrrcc}
\hline & F-Stat & P-value & F-Stat & P-value \\
\hline $\ln$ (oil) & 24.35 & 0.000 & 4.911 & 0.030 \\
$\ln$ (reer) & 14.15 & 0.000 & 0.069 & 0.792 \\
$\ln$ (vix) & 0.1079 & 0.744 & 1.411 & 0.239 \\
$\ln$ (skew) & 0.0013 & 0.997 & 1.849 & 0.178 \\
$\ln$ (pci) & 0.0881 & 0.768 & 2.687 & 0.105 \\
$\ln$ (epu) & 0.2885 & 0.593 & 0.965 & 0.329 \\
\hline
\end{tabular}

Notes: The table reports the results of the long run symmetry tests of the effect of each explanatory variable on the price of gold. We use the Wald statistic for the long-run symmetry, which tests the null hypothesis of $\alpha+=$ $\alpha$ - for each explanatory variable in Equation (7). 
Table 4

Results of the NARDL Estimation

\begin{tabular}{|c|c|c|c|c|c|}
\hline L._y & $\begin{array}{c}-0.445 * * * \\
(0.113)\end{array}$ & L4._dx1p & $\begin{array}{c}-0.244 * \\
(0.144)\end{array}$ & L7._dx3p & $\begin{array}{l}0.116^{*} \\
(0.064)\end{array}$ \\
\hline L._x1p & $\begin{array}{c}0.276 * * \\
(0.125)\end{array}$ & L._dx1n & $\begin{array}{c}0.379 * * * \\
(0.143)\end{array}$ & L8._dx3p & $\begin{array}{c}0.199 * * * \\
(0.065)\end{array}$ \\
\hline L._x $1 \mathrm{n}$ & $\begin{array}{c}-0.455 * * * \\
(0.123)\end{array}$ & L2._dx1n & $\begin{array}{c}0.101 \\
(0.125)\end{array}$ & L10._dx3p & $\begin{array}{c}0.136 * * \\
(0.063)\end{array}$ \\
\hline L._x $2 p$ & $\begin{array}{c}-4.965 * * * \\
(1.266)\end{array}$ & L3._dx1n & $\begin{array}{c}0.167 \\
(0.125)\end{array}$ & _dx3n & $\begin{array}{c}-0.101 * \\
(0.059)\end{array}$ \\
\hline L._x $2 n$ & $\begin{array}{l}-0.148 \\
(0.468)\end{array}$ & L4._dx1n & $\begin{array}{c}0.303 * * \\
(0.118)\end{array}$ & L10._dx3n & $\begin{array}{c}-0.121 * \\
(0.068)\end{array}$ \\
\hline L._x3p & $\begin{array}{l}-0.107 \\
(0.075)\end{array}$ & L8._dx1n & $\begin{array}{l}0.225^{*} \\
(0.119)\end{array}$ & L11._dx3n & $\begin{array}{c}-0.144 * * \\
(0.060)\end{array}$ \\
\hline L._x3n & $\begin{array}{l}-0.147 \\
(0.093)\end{array}$ & _dx2p & $\begin{array}{c}-3.335^{* * *} \\
(0.946)\end{array}$ & $\_\mathrm{dx} 4 \mathrm{p}$ & $\begin{array}{c}0.469^{* *} \\
(0.230)\end{array}$ \\
\hline L._x $4 p$ & $\begin{array}{c}0.373 \\
(0.565)\end{array}$ & L._dx2p & $\begin{array}{c}3.074 * * * \\
(1.053)\end{array}$ & _dx4n & $\begin{array}{c}-0.547 * * \\
(0.236)\end{array}$ \\
\hline L._ $x 4 n$ & $\begin{array}{c}0.372 \\
(0.672)\end{array}$ & L3._dx2p & $\begin{array}{c}2.462 * * \\
(1.153)\end{array}$ & _dx6p & $\begin{array}{l}0.086^{*} \\
(0.045)\end{array}$ \\
\hline L._x5p & $\begin{array}{l}-0.048 \\
(0.207)\end{array}$ & L4._dx2p & $\begin{array}{c}2.553 * * \\
(1.123)\end{array}$ & L8._dx6p & $\begin{array}{c}-0.147 * * \\
(0.060)\end{array}$ \\
\hline L._x5n & $\begin{array}{l}-0.072 \\
(0.189)\end{array}$ & L11._dx2p & $\begin{array}{l}1.574 * \\
(0.875)\end{array}$ & L2._dx6n & $\begin{array}{c}-0.219^{* *} \\
(0.104)\end{array}$ \\
\hline L._x6p & $\begin{array}{l}0.134 * \\
(0.068)\end{array}$ & L8._dx2n & $\begin{array}{c}2.202 * * \\
(0.902)\end{array}$ & L3._dx6n & $\begin{array}{c}-0.193 * \\
(0.101)\end{array}$ \\
\hline _dx1p & $\begin{array}{c}0.318^{* *} \\
(0.135)\end{array}$ & L6._dx3p & $\begin{array}{c}0.166^{* *} \\
(0.069)\end{array}$ & L6._dx6n & $\begin{array}{c}-0.179 * \\
(0.091)\end{array}$ \\
\hline & & & & Constant & $\begin{array}{c}2.743 * * * \\
(0.690)\end{array}$ \\
\hline Observations & 232 & & & & \\
\hline R-squared & 0.784 & & & & \\
\hline
\end{tabular}

Notes: In the output variables are renamed to _y (the endogenous variable), _x1p, _x2p... (The sum of the positive changes in exogenous variables $1,2 \ldots \mathrm{n}$ ), and _x $1 \mathrm{n}, \mathrm{x}_{2} \mathrm{n} . .$. (The sum of the negative changes in exogenous variables $1,2 \ldots)$. A "d" in the variable name indicates the first differences. We also perform the diagnostic statistics, and results are satisfactory. Variables 1,2,3,4,5, and 6 denote the oil price, the real effective exchange rate, the VIX index, the SKEW index, the partisan conflict indexes, and the global economic policy uncertainty, respectively. $*, * *$, and $* * *$ represent $10 \%, 5 \%$, and $1 \%$ significance level respectively. 
Figure 1.

The Cumulative Dynamic Multipliers for the Positive and the Negative Changes in Exogenous Variables
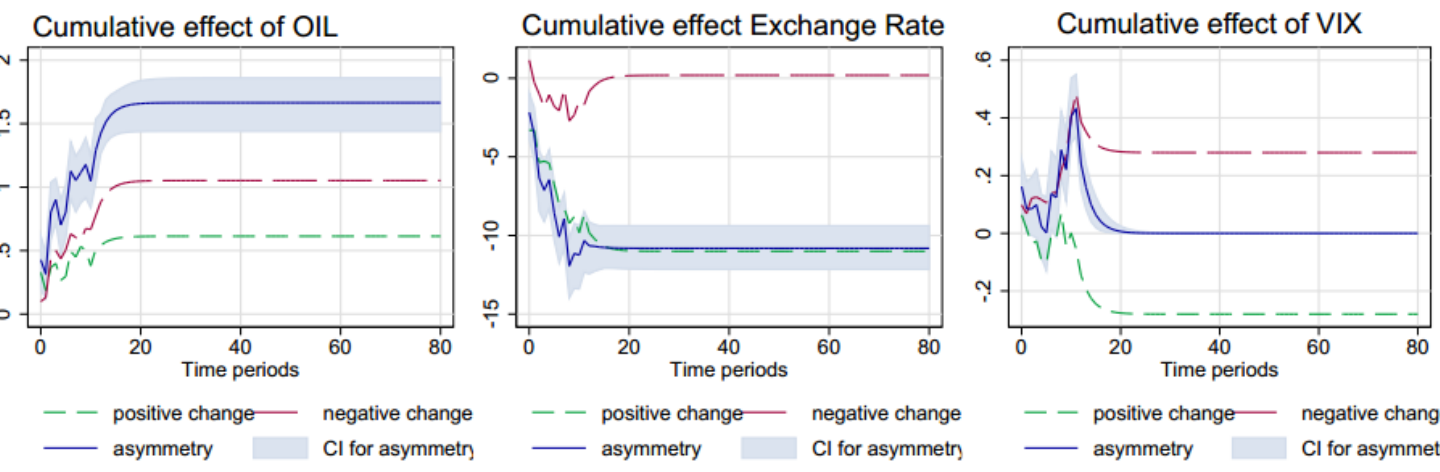

Note: $90 \%$ bootstrap $\mathrm{Cl}$ is based on 100 replications

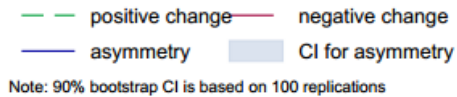

\section{Cumulative effect of SKEW}
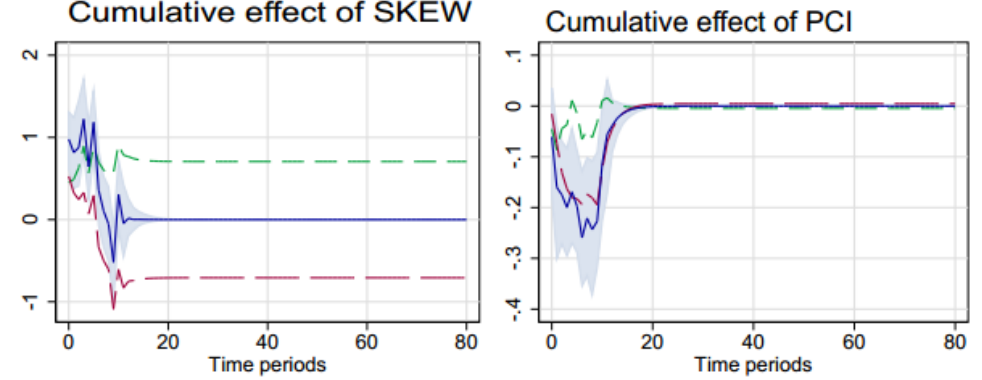

Cumulative effect of EPU

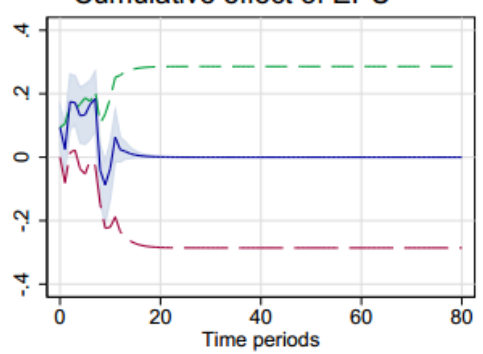

- - positive change - negative change asymmetry $\mathrm{Cl}$ for asymmetr

Note: $90 \%$ bootstrap $\mathrm{Cl}$ is based on 100 replications

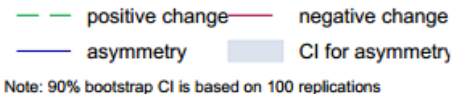

- - positive change- negative change

- asymmetry $\quad \mathrm{Cl}$ for asymmetry

Note: $90 \%$ bootstrap $\mathrm{Cl}$ is based on 100 replications 
Appendix I.

Summary of the Descriptive Statistics and the Description of the Variables

January 1997-May 2017 (245 Observations)

\begin{tabular}{|c|c|c|c|c|c|c|}
\hline Variable & Unit & Measure & Mean & Standard Deviation & Skewness & Kurtosis \\
\hline Price of Gold & Spot Price & Logarithmic Form & 6.473 & 0.660 & -0.016 & 1.391 \\
\hline Price of Oil & Spot Price & Logarithmic Form & 3.851 & 0.611 & -0.349 & 2.429 \\
\hline Real Exchange Rate $(2010=100)$ & USD & Logarithmic Form & 4.693 & 0.086 & -0.030 & 1.971 \\
\hline Volatility & Index & Logarithmic Form & 2.975 & 0.344 & 0.426 & 2.924 \\
\hline SKEW & Index & Logarithmic Form & 4.777 & 0.055 & 0.549 & 3.682 \\
\hline Partisan Conflict & Index & Logarithmic Form & 4.645 & 0.310 & 0.621 & 2.602 \\
\hline Global Economic Policy Uncertainty & Index, (PPP-Adjusted GDP Weights) & Logarithmic Form & 4.605 & 0.388 & 0.496 & 2.745 \\
\hline
\end{tabular}

Appendix II.

Correlation Matrix

\begin{tabular}{|c|c|c|c|c|c|c|c|}
\hline Regressors & Log Price of Gold & Log Price of Oil & Log REER & Log VIX & Log SKEW & Log Partisan Conflict & Log Global EPU (PPP) \\
\hline Log Price of Gold & 1.000 & - & - & - & - & - & - \\
\hline Log Price of Oil & 0.829 & 1.000 & - & - & - & - & - \\
\hline Log REER & -0.788 & -0.797 & 1.000 & - & - & - & - \\
\hline Log VIX & -0.260 & -0.322 & 0.160 & 1.000 & - & - & - \\
\hline Log SKEW & 0.501 & 0.285 & -0.244 & -0.427 & 1.000 & - & - \\
\hline Log Partisan Conflict & 0.745 & 0.449 & -0.454 & -0.346 & 0.594 & 1.000 & - \\
\hline Log Global EPU (PPP) & 0.582 & 0.268 & -0.191 & 0.164 & 0.301 & 0.627 & 1.000 \\
\hline
\end{tabular}

